\title{
Processing homonymy and polysemy: Effects of sentential context and time-course following unilateral brain damage
}

\author{
Ekaterini Klepousniotou $^{\mathrm{a}, \mathrm{b}, \mathrm{c}, *}$, Shari R. Baum ${ }^{\mathrm{a}, \mathrm{c}}$ \\ ${ }^{\text {a }}$ Centre for Research on Language, Mind, and Brain, McGill University, Canada \\ ${ }^{\mathrm{b}}$ Mc Connell Brain Imaging Centre, MNI, McGill University, Canada \\ ${ }^{\mathrm{c}}$ School of Communication Sciences and Disorders, Mc Gill University, Canada
}

Accepted 1 March 2005

Available online 2 April 2005

\begin{abstract}
The present study investigated the abilities of left-hemisphere-damaged (LHD) non-fluent aphasic, right-hemisphere-damaged (RHD), and normal control individuals to access, in sentential biasing contexts, the multiple meanings of three types of ambiguous words, namely homonyms (e.g., "punch"), metonymies (e.g., "rabbit"), and metaphors (e.g., "star"). Furthermore, the predictions of the "suppression deficit" and "coarse semantic coding" hypotheses, which have been proposed to account for RH language function/ dysfunction, were tested. Using an auditory semantic priming paradigm, ambiguous words were incorporated in dominant- or subordinate-biasing sentence-primes followed after a short $(100 \mathrm{~ms})$ or long $(1000 \mathrm{~ms})$ interstimulus interval (ISI) by dominant-meaningrelated, subordinate-meaning-related or unrelated target words. For all three types of ambiguous words, both the effects of context and ISI were obvious in the performance of normal control subjects, who showed multiple meaning activation at the short ISI, but eventually, at the long ISI, contextually appropriate meaning selection. Largely similar performance was exhibited by the LHD nonfluent aphasic patients as well. In contrast, RHD patients showed limited effects of context, and no effects of the time-course of processing. In addition, although homonymous and metonymous words showed similar patterns of activation (i.e., both meanings were activated at both ISIs), RHD patients had difficulties activating the subordinate meanings of metaphors, suggesting a selective problem with figurative meanings. Although the present findings do not provide strong support for either the "coarse semantic coding" or the "suppression deficit" hypotheses, they are viewed as being more consistent with the latter, according to which RH damage leads to deficits suppressing alternative meanings of ambiguous words that become incompatible with the context.
\end{abstract}

(C) 2005 Elsevier Inc. All rights reserved.

Keywords: Brain laterality; Sentential context; Lexical ambiguity; Homonymy; Metonymy; Metaphor

\section{Introduction}

An increasing amount of evidence indicates that both the left $(\mathrm{LH})$ and the right hemisphere $(\mathrm{RH})$ contribute to the comprehension of semantic relations. Although it is well established that the left hemisphere is dominant for language processes, it is now acknowledged that the right hemisphere also possesses certain linguistic abilities. More

\footnotetext{
* Corresponding author. Fax: +1 5143988123 .

E-mail address: ekaterini.klepousniotou@mail.mcgill.ca (E. Klepousniotou).
}

specifically, the RH has been considered to be involved in the comprehension of meanings secondary to the central meaning of a word (i.e., comprehending words that are ambiguous) (e.g., Brownell, Potter, Michelow, \& Gardner, 1984). Nevertheless, the extent of the contribution of each hemisphere to the understanding of the different types of ambiguous words is still under investigation.

According to theoretical linguistics accounts, lexical ambiguity is divided into two types, namely homonymy and polysemy. Homonymy refers to the cases in which a lexical item "accidentally" carries two distinct and unrelated meanings (e.g., "bank $k_{1}$ " which means "financial 
institution" and "bank ${ }_{2}$ " which means "river side"). On the other hand, polysemy refers to the cases in which a single lexical item has multiple related meanings (e.g., "mouth" which refers to "an organ of the body" and to "where a river meets the ocean"). Furthermore, polysemy is divided into metonymic polysemy (i.e., metonymy), in which a relation of connectedness holds between the senses of the word (e.g., "rabbit" refers to the "animal" and to the "meat of that animal"), and metaphorical polysemy (i.e., metaphor), in which a relation of analogy holds between the senses of the word (e.g., "eye" which refers to "an organ of the body" and to the "hole in a needle") (Apresjan, 1974). The two sub-types of polysemy differ in that both the basic and the secondary senses of metonymic polysemy are literal, while the basic sense of metaphorical polysemy is literal, whereas its secondary sense is figurative. However, there are also similarities between the two sub-types of polysemy in that the changes in meaning are productive and can be observed across lexical items of the same category (e.g., all lexical items referring to body parts have figurative extensions that refer to physical objects).

Although two criteria have been proposed for the distinction between homonymy and polysemy, namely the "etymological derivation of words" and the "relatedness/ unrelatedness of meaning," the notions of homonymy and polysemy seem to be relative concepts, as there is no clear dichotomy between the two. Rather, there seems to be a continuum from "pure" homonymy to "pure" polysemy. Along this continuum, theoretical linguists (e.g., Apresjan, 1974; Nunberg, 1979) have argued that metonymy (which is quite regular and productive) seems to be closer to "pure" polysemy, while metaphor (which is considered irregular) may be closer to homonymy. Thus, given these sub-divisions, it is important to investigate whether the three types of lexical ambiguity yield differential patterns of processing. Moreover, exploiting these linguistic distinctions may also help shed more light on the linguistic abilities of the $\mathrm{LH}$ and $\mathrm{RH}$ and their relative contribution to the processing of ambiguous words.

Despite these theoretical distinctions of lexical ambiguity, most work in psycholinguistics has concentrated on homonymy, while polysemous words have sometimes been used interchangeably with homophones, homographs, or homonyms ${ }^{1}$ to test models and theories of lex-

\footnotetext{
${ }^{1}$ Homophones, homographs, and homonyms refer to three subtypes of ambiguous words that have distinct and unrelated meanings. To clarify, homophony is the case where two words have the same pronunciation, but they have different written forms, as for example, "red" which refers to "a color," and "read" which is the past tense form of the verb "to read." Homography, on the other hand, is the case where two words have the same written form, but different pronunciation and meaning, such as "wound ${ }_{1}$ " which is the past tense of the verb "to wind," and "wound ${ }_{2}$ " which means "a sore/cut." Finally, homonymy is the case where both the pronunciation and written form of two words are the same, but they have distinct and unrelated meanings, as for example, "pen 1 " which means "a writing device" and "pen," which means "an enclosure."
}

ical access and lexical ambiguity processing (Schreuder \& Flores d' Arcais, 1989; but cf. Klein \& Murphy, 2001; Rodd, Gaskell, \& Marslen-Wilson, 2002). Looking closely at the results of psycholinguistic studies on lexical ambiguity processing collectively, they seem to point towards a model that lies somewhere between the strong versions of both the selective access (i.e., only contextually appropriate meanings are activated) and the multiple access (i.e., all meanings are activated) models. According to this "hybrid" model, activation of all meanings seems to occur initially. However, within $200 \mathrm{~ms}$ there seems to be selection of the appropriate meaning (e.g., Seidenberg, Tanenhaus, Leiman, \& Bienkowski, 1982; Tanenhaus, Leiman, \& Seidenberg, 1979). A highly constraining context may also lead to selective access of the appropriate meaning only (e.g., Simpson \& Krueger, 1991). Simpson $(1984,1994)$ even suggests that the findings of the studies on lexical ambiguity processing could be better explained by having a model where all meanings are activated, but the degree of activation is sensitive to the relative frequency of the meanings, and the context in which the ambiguous word occurs. This kind of hybrid model, which has actually been proposed by Rayner and his colleagues (e.g., Duffy, Morris, \& Rayner, 1988) and is known as the "reordered access" model, has found empirical support from studies using a variety of methods, such as ambiguity detection (e.g., Neill, Hilliard, \& Cooper, 1988), eye movement tracking (e.g., Duffy et al., 1988), and event-related potentials (ERPs) (e.g., Swaab, Brown, \& Hagoort, 2003).

As far as neurolinguistic studies on lexical ambiguity are concerned, the main issue has been if and how focal brain damage disrupts lexical-semantic processing. Early off-line studies (e.g., Brownell, 1998; Brownell et al., 1984; Brownell, Simpson, Bihrle, Potter, \& Gardner, 1990; Schmitzer, Strauss, \& DeMarco, 1997; Winner \& Gardner, 1977) showed that patients with focal RH damage have problems with lexical ambiguity in general, and metaphor in particular. These researchers compared the performance of RHD, LHD, and normal control individuals by using either sentence/context-picture matching (e.g., Schmitzer et al., 1997; Winner \& Gardner, 1977) or word triad relatedness judgment (e.g., Brownell, 1998; Brownell et al., 1984, 1990) paradigms. Overall, it was found that when individuals with LHD were presented with ambiguous adjectives (e.g., "warm" to refer to "hot" or "loving"), they chose metaphoric interpretations (e.g., "loving") more frequently and they were less likely to select literal foils (e.g., "blanket") than were individuals with RHD. On the other hand, individuals with RHD were as likely to choose metaphoric interpretations as literal ones. In addition, in comparisons of comprehension performance across neutral, connotation-biased and denotation-biased contexts, RHD patients exhibited decreased accuracy levels in the neutral and connotation-biased contexts. Thus, it was 
suggested that secondary or subordinate (i.e., non-literal, connotative) meanings are much less salient when the right hemisphere is dysfunctional (Brownell et al., 1990; Schmitzer et al., 1997).

Based on these early off-line findings, which showed that RHD patients have difficulties with lexical ambiguity, as well as on later studies on lexical ambiguity processing by both normal and brain-damaged populations, two major theories have been proposed to account for the deficits observed after RH damage, namely the "suppression deficit" and the "coarse semantic coding" hypotheses. According to the "suppression deficit" hypothesis, RHD patients' deviant performance with ambiguous words could be attributed to problems with suppressing interpretations that are initially activated, but eventually become irrelevant or incompatible with the context (Tompkins \& Lehman, 1998). The suppression mechanism is compromised in individuals with RHD, and suppression function after RHD is assumed to correlate with comprehension (Tompkins \& Lehman, 1998). The large majority of investigations of the processing of lexical ambiguity in context by individuals with right-hemisphere damage (RHD) has supported the "suppression deficit" hypothesis (e.g., Grindrod \& Baum, 2003; Tompkins, Baumgaertner, Lehman, \& Fossett, 1997; Tompkins, Baumgaertner, Lehman, \& Fassbinder, 2000). In general, these studies have shown that RHD patients seem to be impaired in the appreciation of context which leads them to the ineffective use of contextual cues to eventually suppress inappropriate (or irrelevant) meanings (Tompkins et al., 2000).

The other major hypothesis concerning $\mathrm{RH}$ processing abilities, known as the "coarse semantic coding" hypothesis, has been proposed by Beeman (1998). According to this hypothesis, during word processing, the LH is most selective, strongly activating small semantic fields, while the $\mathrm{RH}$ diffusely activates large semantic fields (Beeman, 1998). In particular, the RH is assumed to coarsely code semantic input resulting in weak activation of large semantic fields, thus allowing for vague interpretations only. Although such semantic processing would make the $\mathrm{RH}$ less effective for selecting the appropriate meaning of single words, it would make it more sensitive to distant semantic overlap and the maintenance of multiple word meanings. In contrast, the LH is assumed to finely code semantic input, so that a word strongly activates a limited subset of semantic features that are related to its primary meaning. As a result, fine semantic coding would make the LH very efficient at selecting the frequent or contextually appropriate meaning for further processing. Support for the "coarse semantic coding" hypothesis primarily comes from divided visual field studies with neurologically intact individuals. These studies have used manipulations of sentential context to demonstrate hemispheric differences in lexical-semantic pro- cessing (e.g., Coney \& Evans, 2000; Faust, Kravetz, \& Netzer, 2002; Titone, 1998). In general, it has been shown that following biased priming sentences at longer intervals, only the contextually appropriate meaning is facilitated in the LH, whereas all related targets (i.e., both contextually appropriate and inappropriate) are facilitated in the RH. In other words, although irrelevant meanings are suppressed in the LH, no suppression or limited suppression effects are observed in the RH (Faust \& Gernsbacher, 1996). These results indicate that the two hemispheres respond differently to lexical ambiguity; the RH maintains activation of all meanings for a longer time, whereas the LH focuses on the most dominant or contextually appropriate meaning of ambiguous words, dampening irrelevant interpretations more quickly.

As discussed, a number of studies has provided evidence in favour of either the "suppression deficit" or the "coarse semantic coding" hypotheses. However, it is not always easy to compare the results of these studies and formulate a unified account of the lexical-semantic abilities of the RH and the deficits observed after RH damage, due to major methodological differences across the investigations. The most crucial methodological difference is that the studies that have supported the "suppression deficit" hypothesis included brain-damaged populations, whereas the studies that provided evidence in favour of the "coarse semantic coding" hypothesis mainly used the divided visual field methodology in nonbrain-damaged individuals. Thus, to date, experiments have been unable to unequivocally support one hypothesis over the other. In other words, neither the "suppression deficit" nor the "coarse semantic coding" hypothesis has garnered clear support. The present study, which uses an auditory sentence priming paradigm, was designed in an attempt to further address this issue by carefully controlling the types of lexical ambiguity under investigation.

Exploiting the theoretical linguistic distinction of lexical ambiguity into homonymy, metaphorical polysemy (i.e., metaphor), and metonymic polysemy (i.e., metonymy) may allow us to contrast more clearly the predictions of the "suppression deficit" and the "coarse semantic coding" hypotheses. In homonymy, a lexical item carries two (or more) distinct and unrelated meanings. Therefore, there is, at best, only a distant semantic relation between the meanings and no strong feature overlap. In contrast, in metonymy, where a single lexical item has several different but related senses, there is a close semantic relation between its senses and strong feature overlap. Although Klein and Murphy (2001) provide evidence that, at least for some polysemous words, their senses seem to be quite distinct, there are other studies that indicate that there are cases (especially in metonymous words) where the senses are very closely related and exhibit strong featural overlap (e.g., Frazier 
\& Rayner, 1990; Klepousniotou, 2002; Rodd et al., 2002). In particular, greater priming effects (Klepousniotou, 2002) and shorter fixation times (Frazier \& Rayner, 1990) have been found for metonymically polysemous words than homonymous words. In addition, there is evidence that ambiguous words with related meanings (and in particular metonymous words) are processed faster than unambiguous words, whereas ambiguous words with unrelated meanings (i.e., homonymous words) do not show such an advantage (Azuma \& Van Orden, 1997; Rodd et al., 2002; but cf. Rubenstein, Lewis, \& Rubenstein, 1971 who found a facilitatory effect of homography only when the alternative meanings are equiprobable and not systematically related). Finally, it has also been found that the various senses of polysemous words are interdependent (Williams, 1992; but cf. Klein \& Murphy, 2001, 2002), and it may not be possible to suppress them even in incongruent contexts (Williams, 1992). These findings suggest that there may be differences in the representations of ambiguous words, depending on whether they have multiple meanings (i.e., homonymy) or multiple senses (i.e., polysemy) (but cf. Klein \& Murphy, 2001, 2002). The present investigation exploits the types of metonymous words that have very closely related senses and, thus, exhibit strong featural overlap. Furthermore, in concert with the notion of a continuum from "pure" homonymy to "pure" polysemy (i.e., metonymy), metaphor seems to be somewhere between the two end-points. Despite the fact that the multiple meanings may be related through analogy, they may not have as strong feature overlap as metonymous words, and thus they may be, in terms of processing, closer to homonymy. Based on the nature of homonymy and metonymy, the "suppression deficit" and the "coarse semantic coding" hypotheses, in their purest versions, make different predictions.

The strongest version of the "suppression deficit" hypothesis would predict that RHD patients would exhibit similar performance for all types of lexical ambiguity. Since all three types (i.e., homonymy, metaphor, and metonymy) involve alternative meanings that must be suppressed, irrespective of whether they are literal or figurative and regardless of the strength of their interrelatedness, individuals with RHD should be equally impaired at suppressing the alternative (contextually inappropriate) meanings of homonymous, metaphorical, and metonymous words, at least at the longer delay (1000 ms ISI).

The "coarse semantic coding" hypothesis, on the other hand, in its strongest version, would predict differential performance depending on the type of ambiguity the lexical items exhibit. The alternative meanings of homonymous words are unrelated and there is very weak feature overlap (which could merely be phonological and/or orthographic), whereas the alternative senses of metonymous words are interrelated and there is strong feature overlap. One might be tempted to suggest no RH involvement in the processing of homonymous words, given that there is no semantic relation between their multiple meanings. However, the vast majority of divided visual field studies provide evidence that although there is distributed activation in both hemispheres, the RH seems to show increased and prolonged activation of peripheral or secondary/subordinate meanings of homonymous words while dominant meanings are mainly activated and maintained in the LH (e.g., Anaki, Faust, \& Kravetz, 1998; Burgess \& Simpson, 1988; Coney \& Evans, 2000; Titone, 1998). Therefore, based on the evidence from divided visual field studies and the assumptions of the "coarse semantic coding" hypothesis, it is predicted that RHD patients should be impaired at accessing the alternative meanings of homonymous and possibly metaphorical words, but not of metonymous words.

It must be noted, however, that the above predictions derive from the purest versions of the "suppression deficit" and "coarse semantic coding" theories in which contextual bias and meaning dominance are not taken into consideration. In fact, neither of the two theories explicitly discusses how contextual bias and meaning dominance may affect the processing of ambiguous words and their predictions about RH involvement in language processes. Nevertheless, if contextual bias and meaning dominance were found to influence the predictions of the two theories, both factors could be integrated into revised versions of the theories, without having to discard their fundamental assumptions.

With respect to the use of context, both the findings of lexical ambiguity studies with non-brain-damaged individuals, as well as the characteristics of RHD patients indicate that it may provide interesting information about the processing of lexical ambiguity. In particular, psycholinguistic studies have shown that the presence of strong contextual cues affects the activation patterns of ambiguous words in non-brain-damaged individuals (e.g., Seidenberg et al., 1982; Swinney, 1979), limiting access to the contextually appropriate meanings. Furthermore, individuals with RHD have been shown to exhibit specific problems in understanding complex contexts (e.g., Beeman, 1993). Therefore, it is crucial to investigate the effects of context on RHD patients, as well as LHD patients, and explore whether the use of context enhances or inhibits the activation of alternative (or inappropriate) meanings.

Another factor manipulated in the present study was the length of the interval (ISI) between prime and target. Previous studies have shown that the interval between prime and target can affect the pattern of activation of the alternative meanings of ambiguous words (e.g., Burgess \& Simpson, 1988; Simpson \& Krueger, 1991; Swinney, 1979). Time-course studies with normal nonbrain-damaged individuals have suggested that short 
intervals (up to $200 \mathrm{~ms}$ approximately) measure immediate activation processes, whereas longer intervals (more than $500 \mathrm{~ms}$ ) measure later post-access selection processes. Furthermore, studies with brain-damaged populations have suggested that patients may not be impaired at activating lexical-semantic information, but rather may be delayed, so that contextual integration and selection processes are obvious only at longer intervals (e.g., Hagoort, 1993; Swaab, Brown, \& Hagoort, 1998; but cf. Milberg, Blumstein, \& Dworetzky, 1987). Given the predictions of the two hypotheses, it is important to investigate whether the performance of RHD patients is actually due to a delay in activation or suppression of alternative word meanings.

Thus, by carefully manipulating the site of lesion (LH, $\mathrm{RH}$ ), the type of context (dominant- or subordinatemeaning biasing), the length of the interstimulus interval (ISI), and the type of ambiguity (i.e., homonymy, metaphor, and metonymy), the present study attempted to shed more light on the time-course of meaning activation in context, as well as test the "suppression deficit" and the "coarse semantic coding" hypotheses of RH language function and dysfunction.

\section{Method}

\subsection{Subjects}

Three groups of subjects participated in the present study: a group of 9 LHD non-fluent aphasic individuals (diagnosed according to results of the BDAE, see below), a group of 8 RHD individuals and a group of 10 normal control individuals matched in mean age to the two brain-damaged groups. All subjects were native speakers of English with hearing within normal limits for their age, as attested by audiometric screening at $\angle 35 \mathrm{~dB} H \mathrm{HL}$ at the speech frequencies of $0.5,1.0$, and $2.0 \mathrm{kHz}$.

Brain-damaged patients were recruited from a number of institutions in the Montreal area, and they had all suffered a single unilateral cerebrovascular accident, confirmed by Computerized Axial Tomography (CT) or Magnetic Resonance Imaging (MRI) scans. Radiological reports of CT and/or MRI scans, as well as neurological reports, determined the lesion sites of the cerebrovascular accidents which were due to hemorrhagic or ischemic infarcts. At the time of the infarct onset, most brain-damaged individuals had motor deficits on the contralateral side to their lesions.

Tables 1 and 2 provide information about the etiology and lesion site of the brain-damaged individuals. Based on the CT/MRI scans and the neurological reports, five of the eight RHD patients [R03, R04, R05, $\mathrm{R} 06, \mathrm{R} 07]$ had a lesion that involved the territory of the right lateral cerebral cortex that is supplied with blood by the middle cerebral artery (MCA) (see Table 2). RHD patients with lesions in the territory of the right MCA were chosen to match the type of lesions primarily observed in LHD non-fluent aphasic patients. The other three patients [R01, R02, and R08] had primarily subcortical lesions involving the right cerebral hemisphere. In summary, the present group of RHD patients had $\mathrm{RH}$ lesions (either cortical or subcortical) affecting the function of the right cerebral hemisphere. With regard to the LHD non-fluent aphasic patients, as can be seen in Table 1, they had lesions resulting from infarcts in the territory of the left middle cerebral artery affecting the function of the left lateral cerebral cortex. The presence of multiple infarcts, a history of drug or alcohol abuse, or a history of psychiatric and/or neurological disorders constituted criteria for initial exclusion. The brain-damaged patients were at least six months post-onset at the

Table 1

Background information of non-fluent aphasic (LHD) individuals

\begin{tabular}{|c|c|c|c|c|c|c|c|c|c|}
\hline \multirow[t]{2}{*}{ Patient } & \multirow[t]{2}{*}{ Age (years) } & \multirow[t]{2}{*}{ Education $^{\mathrm{a}}$ (years) } & \multirow[t]{2}{*}{ Sex } & \multirow[t]{2}{*}{ Etiology } & \multirow[t]{2}{*}{ Lesion site ${ }^{b}$} & \multirow[t]{2}{*}{ MPO } & \multirow{2}{*}{$\begin{array}{l}\mathrm{BDAE} \\
\mathrm{AC}(\%)\end{array}$} & \multicolumn{2}{|l|}{ PAL } \\
\hline & & & & & & & & SWPM (/32) & $\operatorname{ASC}(/ 40)$ \\
\hline L01 & 54 & 14 & M & I & L MCA (parietal) & 184 & 90 & 32 & 32 \\
\hline L02 & 71 & 9 & $\mathrm{~F}$ & $\mathrm{H}$ & L MCA (fronto-temporo-parietal) & 115 & 60 & 32 & 27 \\
\hline L03 & 82 & 9 & M & I & L MCA (frontal) & 92 & 88.75 & 30 & 34 \\
\hline L04 & 74 & 12 & $\mathrm{~F}$ & I & L MCA (parietal) & 116 & 88.75 & 32 & 40 \\
\hline L05 & 60 & 20 & M & I & L cortical/subcortical & 47 & 30 & 31 & 31 \\
\hline L06 & 69 & 12 & $\mathrm{~F}$ & I & L MCA (fronto-parietal) & 92 & 82.5 & 32 & 30 \\
\hline L07 & 50 & 14 & $\mathrm{~F}$ & I & L MCA (fronto-parietal) & 137 & 87.5 & 31 & 36 \\
\hline L08 & 58 & 11 & $\mathrm{~F}$ & I & L MCA territory & 48 & 50 & 32 & 30 \\
\hline L09 & 58 & 10 & M & I & $\mathrm{L}$ carotid artery ischemia & 38 & 84 & 32 & 37 \\
\hline Mean & 64.0 & 12.3 & & & & 96.6 & 73.5 & 31.6 & 33.0 \\
\hline$S D$ & 10.5 & 3.4 & & & & 47.8 & 21.7 & 0.7 & 4.1 \\
\hline
\end{tabular}

Note. L, left hemisphere; H, hemorrhagic infarct; I, ischemic infarct; MCA, middle cerebral artery; MPO, months post-onset; BDAE, Boston Diagnostic Aphasia Examination; AC, Auditory Comprehension (percentage score); PAL, Psycholinguistic Assessment of Language; SWPM, Spoken Word-Picture Matching (maximum score, 32); ASC, Auditory Sentence Comprehension (maximum score, 40).

a Best estimated conversion into years, based on information from subject (e.g., 2 years college, high school).

b Established on the basis of CT/MRI scans and/or neurological reports. 
Table 2

Background information of right hemisphere damaged (RHD) individuals

\begin{tabular}{|c|c|c|c|c|c|c|c|c|c|}
\hline \multirow[t]{2}{*}{ Patient } & \multirow[t]{2}{*}{ Age (years) } & \multirow[t]{2}{*}{ Education $^{\mathrm{a}}$ (years) } & \multirow[t]{2}{*}{ Sex } & \multirow[t]{2}{*}{ Etiology } & \multirow[t]{2}{*}{ Lesion site $^{\mathrm{b}}$} & \multirow[t]{2}{*}{ MPO } & \multicolumn{2}{|c|}{ TLC-E (adapted) } & \multirow{2}{*}{$\begin{array}{l}\text { PAL } \\
\text { ASC (/40) }\end{array}$} \\
\hline & & & & & & & Fig $(/ 10)$ & $\operatorname{Inf}(/ 10)$ & \\
\hline R01 & 62 & 13 & $\mathrm{~F}$ & $\mathrm{H}$ & R PCoA territory & 152 & 8 & 10 & 40 \\
\hline R02 & 68 & 13 & $\mathrm{~F}$ & $\mathrm{H}$ & $\mathrm{R}$ internal capsule/basal ganglia & 92 & 5 & 9 & 39 \\
\hline R03 & 37 & 13 & $\mathrm{~F}$ & I & R MCA (parietal) & 89 & 9 & 10 & 38 \\
\hline R04 & 65 & 12 & M & I & R MCA territory & 24 & 7 & 6 & 35 \\
\hline R05 & 45 & 9 & $\mathrm{~F}$ & I & R MCA territory & 71 & 6 & 4 & 36 \\
\hline R06 & 90 & 11 & M & $\mathrm{H}$ & R MCA territory & 70 & 7 & 6 & 38 \\
\hline R07 & 81 & 11 & M & I & R MCA (fronto-temporo-parietal) & 65 & 7 & 7 & 37 \\
\hline R08 & 73 & 14 & M & $\mathrm{H}$ & $\mathrm{R}$ thalamus & 72 & 6 & 7 & 37 \\
\hline Mean & 65.1 & 12.0 & & & & 79.4 & 6.9 & 7.4 & 37.5 \\
\hline$S D$ & 17.5 & 1.6 & & & & 35.9 & 1.2 & 2.1 & 1.6 \\
\hline
\end{tabular}

Note. R, right hemisphere; H, hemorrhagic infarct; I, ischemic infarct; MCA, middle cerebral artery; PCoA, posterior communicating artery; MPO, months post-onset; TLC-E, Test of Language Competence-Expanded Edition; Fig, figurative language (maximum score, 10); Inf, inferences (maximum score, 10); PAL, Psycholinguistic Assessment of Language; ASC, Auditory Sentence Comprehension (maximum score, 40).

a Best estimated conversion into years, based on information from subject (e.g., 2 years college, high school).

b Established on the basis of CT/MRI scans and/or neurological reports.

time of testing, and the two brain-damaged groups did not significantly differ in the number of months post-onset of stroke $[F(1,15)=0.686, p=.42]$.

A series of screening and diagnostic tests were administered to the brain-damaged patients. The diagnostic tests differed (in part) across the groups given that left and right hemisphere lesions typically lead to different types of impairments. In particular, the diagnosis of type of aphasia exhibited by the LHD patients was determined by results of the Boston Diagnostic Aphasia Examination (BDAE) (Goodglass, Kaplan, \& Barresi, 2001). On the other hand, RHD patients do not typically exhibit aphasic-like linguistic impairments. For the present group of RHD patients, this was confirmed by clinical records and neurological reports. However, RHD patients do exhibit more subtle linguistic impairments in making inferences and comprehending figurative language. Therefore, they were subjected to a test battery adapted from the Test of Language CompetenceExpanded Edition (TLC-E) (Wiig \& Secord, 1987) to examine inferencing and figurative language abilities; they were also tested on sections of an Emotional Prosody Battery. As can be seen in Table 2, RHD patients indeed exhibited problems with inferencing and figurative language typically observed in this subject population. Overall, the screening tests were used to ensure that the brain-damaged patients participating in the study had representative impairments typically observed in LHD non-fluent aphasic and RHD individuals, respectively.

In addition, both groups of brain-damaged individuals were administered further tests in order to ensure that they had adequate speech and language skills necessary for their participation in the study, and in particular, adequate auditory comprehension of single words and simple sentences so that the task materials and instructions would be understood. It should be noted, however, that comprehension impairments associated with syntactically complex sentences or discourse-level passages were not grounds for exclusion. The additional tests included: the Bells test and sections (line crossing, letter cancellation, star cancellation, figure and shape copying, line bisection, and representational drawing) of the Behavioural Inattention Test (BIT) (Wilson, Cockburn, \& Halligan, 1987) to screen for visual neglect, an Auditory Digit Span test, as well as a series of tests to ensure speech and language skills including the Written Word-Picture Matching subtest, and the Spoken WordPicture Matching subtest, and the Auditory Sentence Comprehension subtest from the Psycholinguistic Assessment of Language (PAL) (Caplan, 1992).

The normal control (NC) group was selected from volunteers in the Montreal area. They were matched as closely as possible to the brain-damaged groups for mean age $(M=69.8, \mathrm{SD}=4.4)$, sex and education level $(M=14, \quad \mathrm{SD}=3.7) \quad($ see Table 3$)$. Normal control

Table 3

Background information of normal control individuals

\begin{tabular}{llll}
\hline Subject & Age (years) & Education $^{\text {a }}$ (years) & Sex \\
\hline C01 & 71 & 9 & $\mathrm{M}$ \\
C02 & 66 & 11 & $\mathrm{M}$ \\
C03 & 69 & 18 & $\mathrm{~F}$ \\
C04 & 69 & 13 & $\mathrm{~F}$ \\
C05 & 70 & 9 & $\mathrm{M}$ \\
C06 & 75 & 14 & $\mathrm{M}$ \\
C07 & 67 & 13 & $\mathrm{~F}$ \\
C08 & 68 & 16 & $\mathrm{~F}$ \\
C09 & 79 & 18 & $\mathrm{~F}$ \\
C10 & 64 & 19 & $\mathrm{M}$ \\
Mean & 69.8 & 14.0 & \\
$S D$ & 4.4 & 3.7 & \\
\hline
\end{tabular}

Note. C, control subjects.

a Best estimated conversion into years, based on information from subject (e.g., 2 years college, high school). 
subjects had no history of neurological and/or psychiatric illness, or speech-language disorders. To exclude the possibility of cognitive decline or dementia, a series of neuropsychological tests were used to screen all control subjects. These tests included the Boston Naming Test (BNT) (Kaplan, Goodglass, \& Weintraub, 1983), the Mini-Mental State Examination (MMSE) (Folstein, Folstein, \& McHugh, 1975), and the Logical Memory I (immediate recall) and II (delayed recall) subtests of the Wechsler Memory Scale-Revised (WMS-R) (Wechsler, 1987). Overall, the three participant groups did not differ significantly in terms of mean age $[F(2,24)=$ $0.675, p=.518]$ or education $[F(2,24)=1.097, p=.349]$. A summary of neuroradiological, demographic, and language performance data for the LHD non-fluent aphasic and RHD individuals as well as for the normal control individuals is presented in Tables 1-3, respectively.

\subsection{Materials}

Prime-target pairs representing three distinct types of lexical ambiguity were constructed in the following way. Eighteen of each of the three types of ambiguous words were selected as primes: (1) unbalanced homonymous words (e.g., "bank") (i.e., one meaning was more frequent (i.e., dominant) than the other meaning (i.e., subordinate)); (2) metaphorical words (e.g., "mouth"); and (3) metonymous words (e.g., "rabbit").

Unbalanced homonymous words were chosen from standardized lists of ambiguous words (e.g., Nelson, McEvoy, Walling, \& Wheeler, 1980; Twilley, Dixon, Taylor, \& Clark, 1994). The frequency of occurrence of the dominant meaning was never less than $63 \%$ and the frequency of occurrence of the subordinate meaning was never greater than $32 \%$. Overall, the dominant meaning had a mean frequency of occurrence of $77 \%$ (range: $63-$ $93 \%$ ) and the subordinate meaning had a mean frequency of $15 \%$ (range: $2-32 \%$ ). The average frequency of occurrence of the homonymous words was 36 (range: 1120) (Francis \& Kucera, 1982). In the present study, the choice of unbalanced homonymous words was dictated by the predictions of the "coarse semantic coding" hypothesis. In particular, according to this hypothesis, the LH subserves dominant meanings while the RH subserves alternative interpretations. Thus, in order to maximize the possibility that alternative meanings are in the realm of the RH, homonymous words with a clear distinction between dominant and subordinate meanings were chosen (i.e., unbalanced homonymous words).

Standardized lists of metonymous and metaphorical words do not exist; therefore, these words were chosen so as to exhibit specific relations between their two senses as documented in the theoretical linguistics literature (e.g., Nunberg, 1979; Pustejovsky, 1995). To control for repetition effects and semantic facilitation effects from an experimental stimulus to another, as well as to investigate the effects of a broader range of words with metonymic and metaphorical meaning extensions, multiple types of metonymous and metaphorical words were included. In particular, metonymous words exhibited the following three types of metonymic relations: 6 words with the count/mass relation (e.g., "rabbit" $\rightarrow$ "the animal" and "the meat of that animal"); 6 words with the container/containee relation (e.g., "bottle" $\rightarrow$ "the container" and "the contents in it"); and 6 words with the figure/ground reversals relation (e.g., "cage" $\rightarrow$ "the actual object" and "the space that is enclosed within it"). The mean frequency of occurrence for the metonymous words was 26 (range: 7-99) (Francis \& Kucera, 1982). Similarly, metaphorical words exhibited three types of metaphorical relations, namely 6 body part/object words (e.g., "mouth" $\rightarrow$ "an aperture on the face" and "where a river meets the ocean"), 6 animal/human characteristic words (e.g., "fox" $\rightarrow$ "a wild animal of the forest" and "a sly and cunning individual"), and 6 physical object/ human characteristic words (e.g., "star" $\rightarrow$ "a bright object in the night sky" and "a famous individual"). The average frequency of occurrence of the metaphorical words was 30 (range: 1-103) (Francis \& Kucera, 1982). Standard dictionaries were consulted to verify the classification of all stimuli as homonymous, metonymous or metaphorical (see also Rodd et al., 2002). All such dictionaries respect the distinction between homonymy and polysemy by listing the different meanings of homonymous words as separate entries, whereas the different senses of metonymous and metaphorical words are listed within a single entry. In addition, all standard dictionaries respect sense dominance by listing the central or dominant sense of metonymous and metaphorical words first and then providing the extended or subordinate senses. Finally, all ambiguous prime words (i.e., homonyms, metonymies, and metaphors) were matched for frequency of occurrence (Francis \& Kucera, 1982), syllable length, concreteness, and grammatical category (see Appendix A).

Ambiguous words were incorporated in sentences that biased one or the other meaning of the ambiguous lexical item which always appeared in the sentence-final position. Thus, each of the three types of ambiguous words (i.e., homonymy, metaphor, and metonymy) was incorporated in two meaning bias conditions (i.e., dominant-meaning bias and subordinate-meaning bias). Sentence primes were constructed with the restriction that word associates of the ambiguous words were not included in the sentences, so that the whole context, rather than an individual word, biased the meanings. Sentence primes were matched for length (5-8 words) and syntactic complexity (only active voice sentences).

To ensure that the sentences actually biased the appropriate meaning of the sentence-final ambiguous word and the associated target word, a sentence rating 
study was conducted. A (different) group of 30 healthy young individuals was asked to rate the relatedness of the target word to the sentence prime. The two sentences that were constructed for each ambiguous word to bias either the dominant or the subordinate meaning (with the ambiguous word underlined in sentence-final position) were followed by a single target word which was either related or unrelated to the priming sentence. The participants were asked to read the sentences carefully and rate how related that single word was to the meaning suggested by the sentence. The rating scale ranged from 1 to 7 , and the participants were instructed to circle 1 if they thought that the sentence and the single word were not related at all. They were instructed to circle 7 if they thought that the sentence and the single word were strongly related, and to use numbers $2-6$ to indicate intermediate levels of relatedness. To avoid repetition of the ambiguous words, two lists of sentences were constructed and were administered with an interval of 10 days. No sentence prime or target word was repeated in the same list. A target word was considered to be unrelated to the biasing sentence if it received a mean rating of less than 1.5 (out of 7), while a target word was considered related if it received a mean rating above 4 (out of 7). Eight sentence-target word pairs, which did not conform to the criteria, were modified and rated again. Overall, unrelated target words had a mean relatedness rating of 1.06 (out of 7; range: 1-1.5), whereas related target words had a mean relatedness rating of 5.93 (out of 7; range: 4.1-6.97). More specifically, for the homonymous words, unrelated target words had a mean relatedness rating of 1.06 (out of 7; range: 1-1.2), whereas dominant-meaning-related target words had a mean relatedness rating of 6.11 (out of 7; range: 4.77-6.8) and subordinate-meaning-related target words had a mean relatedness rating of 5.91 (out of 7; range: 4.13-6.87). For the metonymous words, unrelated target words had a mean relatedness rating of 1.05 (out of 7; range: 1-1.4), whereas dominant-meaning-related target words had a mean relatedness rating of 6.12 (out of 7; range: $4.8^{-}$ 6.97) and subordinate-meaning-related target words had a mean relatedness rating of 5.96 (out of 7; range: $4.47-$ 6.73). Finally, for the metaphorical words, unrelated target words had a mean relatedness rating of 1.08 (out of 7; range: 1-1.5), whereas dominant-meaning-related target words had a mean relatedness rating of 5.78 (out of 7; range: 4.1-6.77) and subordinate-meaning-related target words had a mean relatedness rating of 5.71 (out of 7; range: 4.63-6.83).

Four types of auditory targets were used: (1) words related to the dominant meaning of the ambiguous word primes; (2) words related to the subordinate meaning of the ambiguous word primes; (3) control words unrelated to the ambiguous word primes; and (4) legal non-words. Target words were matched as closely as possible for frequency of occurrence (Francis \& Kucera, 1982), syllable length, and concreteness (see Appendix A). Target nonwords were constructed respecting the phonotactic rules of English.

Word associates for the homonymous, metonymous, and metaphorical words with the animal/human characteristic relation were obtained from a standardized list of word association norms (Nelson, McEvoy, \& Schreiber, 1998). For the metaphorical words exhibiting body part/ object relations (e.g., "mouth") and object/human characteristic relations (e.g., "star"), which did not appear in the word association norms, a word association study was administered. A (different) group of 30 healthy young individuals was asked to generate the first three words associated with a given ambiguous word. Responses were grouped according to the general meaning they conveyed (e.g., for the metaphorically polysemous word "nucleus," the first meaning group was "chemistry" and the second meaning group was "basis of a community"). Only ambiguous words for which word associates for both their meanings were given by more than $80 \%$ of the participants were used in the priming study.

In the experiment, each sentence prime (either dominant or subordinate) was followed either by a target word related to the sentence-final ambiguous word (thus being either contextually appropriate or inappropriate), an unrelated control target word, or a non-word (see Table 4 for examples). Overall, there were a total of 108 priming sentences (54 sentences biasing the dominant meaning, and 54 biasing the subordinate meaning), 162 target words and an equal number of target non-words. Non-words were presented following sentence primes that had the same characteristics as the experimental sentence primes (e.g., type of ambiguous word in sentence-final position, length, and syntactic complexity), but were not part of the experimental sentence group. All stimuli were recorded by a female native speaker of English, digitized at a rate of $20 \mathrm{k}$ samples/second and low pass filtered at $9 \mathrm{kHz}$ using the Brown Lab Interactive Speech System (BLISS) software (Mertus, 2000).

The interval (ISI) between the offset of the sentence prime and the onset of the target item was manipulated in order to investigate the time-course of activation. Based on previous studies (e.g., Burgess \& Simpson, 1988; Tompkins et al., 2000), a short (100 ms) and a long $(1000 \mathrm{~ms})$ interval were chosen to explore immediate versus more delayed processes of meaning activation (and suppression). Each trial consisted of the auditory presentation of a biasing sentence prime and a target (either word or non-word).

To reduce the number of repetitions of the sentence primes and targets, three separate lists of stimuli were constructed for each ISI, presented across three test sessions each at least one week apart. One third of the experimental stimuli comprised each of the three lists. Thus, each list had 54 sentences biasing the sentence- 
Table 4

Examples of dominant- and subordinate-biasing sentences followed by both related and unrelated target words for the homonymy, metonymy and metaphor conditions

\begin{tabular}{|c|c|c|c|c|}
\hline \multirow[t]{3}{*}{ Meaning bias } & \multirow[t]{3}{*}{ Sentence prime } & \multicolumn{3}{|c|}{ Target word } \\
\hline & & \multicolumn{2}{|l|}{ Related } & \multirow[t]{2}{*}{ Unrelated } \\
\hline & & Dominant & Subordinate & \\
\hline \multicolumn{5}{|l|}{ Homonymy } \\
\hline Dominant bias & His nose bled after the powerful punch. & fist & fruit & cloud \\
\hline Subordinate bias & For the party, she prepared a punch. & fist & fruit & cloud \\
\hline \multicolumn{5}{|l|}{ Metonymy } \\
\hline Dominant bias & In the supermarket, she chose a big potato. & spud & mash & claw \\
\hline Subordinate bias & For lunch, she only had some potato. & spud & mash & claw \\
\hline \multicolumn{5}{|l|}{ Metaphor } \\
\hline Dominant bias & The core of the atom is the nucleus. & electron & boss & motel \\
\hline Subordinate bias & Undoubtedly, Tim is the company's nucleus. & electron & boss & motel \\
\hline
\end{tabular}

final ambiguous words toward their dominant meanings and 54 sentences biasing the subordinate meanings. One third of the biasing sentences were followed by a target word associated with the dominant meaning of the ambiguous word, one third were followed by a target word associated with the subordinate meaning, and one third of the sentence primes were followed by an unrelated control target word. No sentence primes or target words were repeated in the same list. A total of 108 experimental sentences and word targets were presented in each list. An equal number of filler sentence primes followed by target non-words were also included in each list. Thus, each list included 216 sentence primes and targets (words and non-words), and there was an equal number of "yes" and "no" responses.

\subsection{Procedure}

All participants were tested in three sessions, each lasting approximately $1 \mathrm{~h}$. A practice session of 6 trials preceded the presentation of the actual experiment. During a single test session, two different lists were presented with a $20 \mathrm{~min}$ break between them. One list was presented at a $100 \mathrm{~ms}$ ISI, whereas the other had a $1000 \mathrm{~ms}$ ISI. Items within a list were presented in fixed random order. The order of presentation of the lists was counterbalanced across subjects within each group (NC, LHD, and RHD). The study was completed in three sessions, after all lists in both ISIs had been presented to the subjects. Test sessions were administered with an interval of a week between them to avoid any carry-over repetition effects.

Participants were tested individually, seated in a comfortable position. They were wearing headphones and the volume was adjusted to their preference. Each trial began with the auditory presentation of a sentence prime through the headphones. At $100 \mathrm{~ms}$ or $1000 \mathrm{~ms}$ after the offset of the sentence prime, an auditory target was presented for lexical decision. Participants were told that they would first hear a sentence and then they would hear a single word, and they would have to make lexical decisions only about the word. They were instructed to respond as accurately and as quickly as possible on a response box located in front of them (using their currently dominant hand) by pressing the YES key if they thought the single word was a real word in English, and the NO key if they thought it was a non-word. Reaction times (in ms) and accuracy rate were recorded by the computer.

\section{Results}

Error rates for lexical decision responses were first examined. For each subject, error rates were calculated for each ISI condition separately. A cutoff accuracy rate of $67 \%$ per list was used, so that the data of any subject who made more than $33 \%$ errors in a single list would be removed from further analysis. No subject reached the cutoff point for any of the lists; furthermore, no differences were observed across test sessions. Thus, the data of all the lists were used in the statistical analyses. In addition, given that unrelated target words acted as controls for both dominant- and subordinate-related target words, if an error was made on an experimental target word (dominant- or subordinate-related), the corresponding control word was still included in the statistical analyses. Due to the limited number of errors and the lack of variance for the NC subjects, statistical analyses were not carried out. For the brain-damaged groups, the results of the error analyses paralleled the reaction time results to be described below. Therefore, the discussion will be restricted to the results of the reaction time (RT) data.

Only correct responses to word targets were analyzed. Prior to statistical analysis, errors and outliers $( \pm 2 S D$ from each subject's mean per condition) were removed. Due to within subject group variability, the reaction time data were normalized using a log transformation (Stevens, 1996). The log transformed data were then 
subjected to 2 (ISI) $\times 2$ (Meaning bias) $\times 3$ (Ambiguity type) $\times 3$ (Target type) repeated measures analyses of variance (ANOVA) for subjects $(F 1)$ and items $(F 2)$ for each subject group separately, in keeping with other research that has used similar analyses (e.g., Hagoort, 1993; Hagoort, Brown, \& Swaab, 1996; Swaab et al., 1998; Tompkins et al., 2000).

\subsection{Normal control subjects}

For the normal control (NC) subjects, errors and outliers $( \pm 2 S D)$ comprised $6.41 \%$ of the data for the short ISI (100 ms) and $6.96 \%$ for the long (1000 ms) ISI.

The ISI (short, long) $\times$ Meaning bias (dominant, subordinate) $\times$ Ambiguity type (homonymy, metonymy, and metaphor) $\times$ Target type (dominant-related, subordinate-related, and unrelated) ANOVA revealed significant main effects of ISI $^{2} \quad[F 1(1,9)=47.78, \quad p<.0001$; $F 2(1,611)=112.68, p<.0001]$, Ambiguity type $[F 1(2,18)=$ $13.00, p<.001 ; F 2(2,611)=7.16, p<.001]$, and Target type $[F 1(2,18)=46.67, p<.0001 ; F 2(2,611)=31.97, p<.0001]$.

There were also significant two-way interaction effects of Meaning bias $\times$ Ambiguity type (for subjects) $[F 1(2,18)=5.12, \quad p<.05 ; \quad F 2(2,611)=1.88, \quad p=.153]$, ISI $\times$ Target type $[F 1(2,18)=3.82, p<.05 ; F 2(2,611)=$ $2.50, p=.082]$, Meaning bias $\times$ Target type $[F 1(2,18)=$ $30.81, p<.0001 ; F 2(2,611)=10.62, p<.0001]$, as well as a significant three-way interaction of ISI $\times$ Meaning bias $\times$ Target type (for subjects) $[F 1(2,18)=3.82, p<.05$; $F 2(2,611)=1.18, p=.308]$.

Post hoc comparisons using the Duncan test $(p<.05)$ to further explore the Meaning bias $\times$ Ambiguity type interaction did not reveal any differences of interest. Comparisons to further explore the ISI $\times$ Target type interaction revealed that for both the short and the long ISIs, RTs to dominant- and subordinate-related targets were significantly faster than to control-unrelated targets (see Fig. 1). Inspection of the individual data ${ }^{3}$ revealed that this pattern of performance was evidenced by $90 \%$ of NC subjects for the short ISI and $70 \%$ of $\mathrm{NC}$ subjects for the long ISI.

In addition, post hoc comparisons to further explore the Meaning bias $\times$ Target type interaction revealed that after dominant-meaning biasing sentences, RTs to dominant- and subordinate-related targets were significantly faster than to unrelated control targets (see Fig. 1). Inspection of the individual data revealed that this pat-

\footnotetext{
${ }^{2}$ Note that the overall reaction times for the normal control subjects are much longer at the long ISI compared to the short ISI, while this difference does not exist for the two brain-damaged subject groups. This could probably be attributed to the fact that the brain-damaged subjects were already performing quite slowly at the short ISI, making it impossible to exhibit substantially slower responses at the long ISI.

${ }^{3}$ When referring to individual data, a difference of at least $20 \mathrm{~ms}$ was arbitrarily considered to be reaction time facilitation.
}

tern of performance was evidenced by $100 \%$ of NC subjects for the dominant-related targets and by $90 \%$ of $\mathrm{NC}$ subjects for the subordinate-related targets. Similarly, after subordinate-meaning biasing sentences, RTs both to dominant- and subordinate-related targets were significantly faster than to unrelated control targets (see Fig. 1). Inspection of the individual data revealed that this pattern of performance was evidenced by $80 \%$ of $\mathrm{NC}$ subjects for the dominant-related targets and $100 \%$ of NC subjects for the subordinate-related targets.

Most importantly, post hoc comparisons exploring the ISI $\times$ Meaning bias $\times$ Target type interaction showed that, for the short $(100 \mathrm{~ms})$ ISI, after dominant-meaning biasing sentences, RTs to both dominant- and subordinate-related targets were significantly faster than to unrelated control targets (see Fig. 1). Inspection of the individual data revealed that this pattern of performance was evidenced by $100 \%$ of NC subjects. Similarly, after subordinate-meaning biasing sentences, RTs to both dominant- and subordinate-related targets were significantly faster than to unrelated control targets (as evidenced by $90 \%$ of NC subjects) (see Fig. 1). For the long $(1000 \mathrm{~ms})$ ISI, however, following dominant-meaning biasing sentences, only dominant-related targets were facilitated (shown by $70 \%$ of NC subjects, while $30 \%$ showed facilitation for both dominant- and subordinaterelated targets), whereas following subordinate-meaning biasing sentences, only subordinate-related targets were facilitated (as evidenced by $60 \%$ of NC subjects, while $30 \%$ showed facilitation for both dominant- and subordinate-related targets) (see Fig. 1).

\subsection{LHD non-fluent aphasic subjects}

For the LHD non-fluent aphasic subjects, errors and outliers $( \pm 2 S D)$ comprised $12.68 \%$ of the data for the short ISI $(100 \mathrm{~ms})$ and $10.83 \%$ for the long $(1000 \mathrm{~ms})$ ISI.

The ISI (short, long) $\times$ Meaning bias (dominant, subordinate) $\times$ Ambiguity type (homonymy, metonymy, metaphor) $\times$ Target type (dominant-related, subordinate-related, unrelated) ANOVA revealed significant main effects of ISI (marginally for subjects) $[F 1(1,8)=$ $3.61, p<.09 ; F 2(1,612)=7.15, p<.01$ ], Meaning bias (for subjects) $[F 1(1,8)=7.22, p<.05 ; F 2(1,612)=1.96, p=$ $.162]$, Ambiguity type $[F 1(2,16)=16.15, \quad p<.001$; $F 2(2,612)=6.00, p<.01]$, and Target type $[F 1(2,16)=$ $44.89, p<.0001 ; F 2(2,612)=26.75, p<.0001]$.

There were also significant two-way interaction effects of ISI $\times$ Meaning bias $[F 1(1,8)=5.73, p<.05 ; F 2(1$, $612)=8.48, p<.01]$ and Meaning bias $\times$ Target type $[F 1(2,16)=8.01, p<.01 ; F 2(2,612)=3.57, p<.05]$. Furthermore, there was a trend toward a three-way interaction of ISI $\times$ Meaning bias $\times$ Target type (for subjects) $[F 1(2,16)=2.85, p<.08 ; F 2(2,612)=1.13, p=.323]$.

Post hoc comparisons using the Duncan test $(p<.05)$ to further explore the ISI $\times$ Meaning bias interaction did 

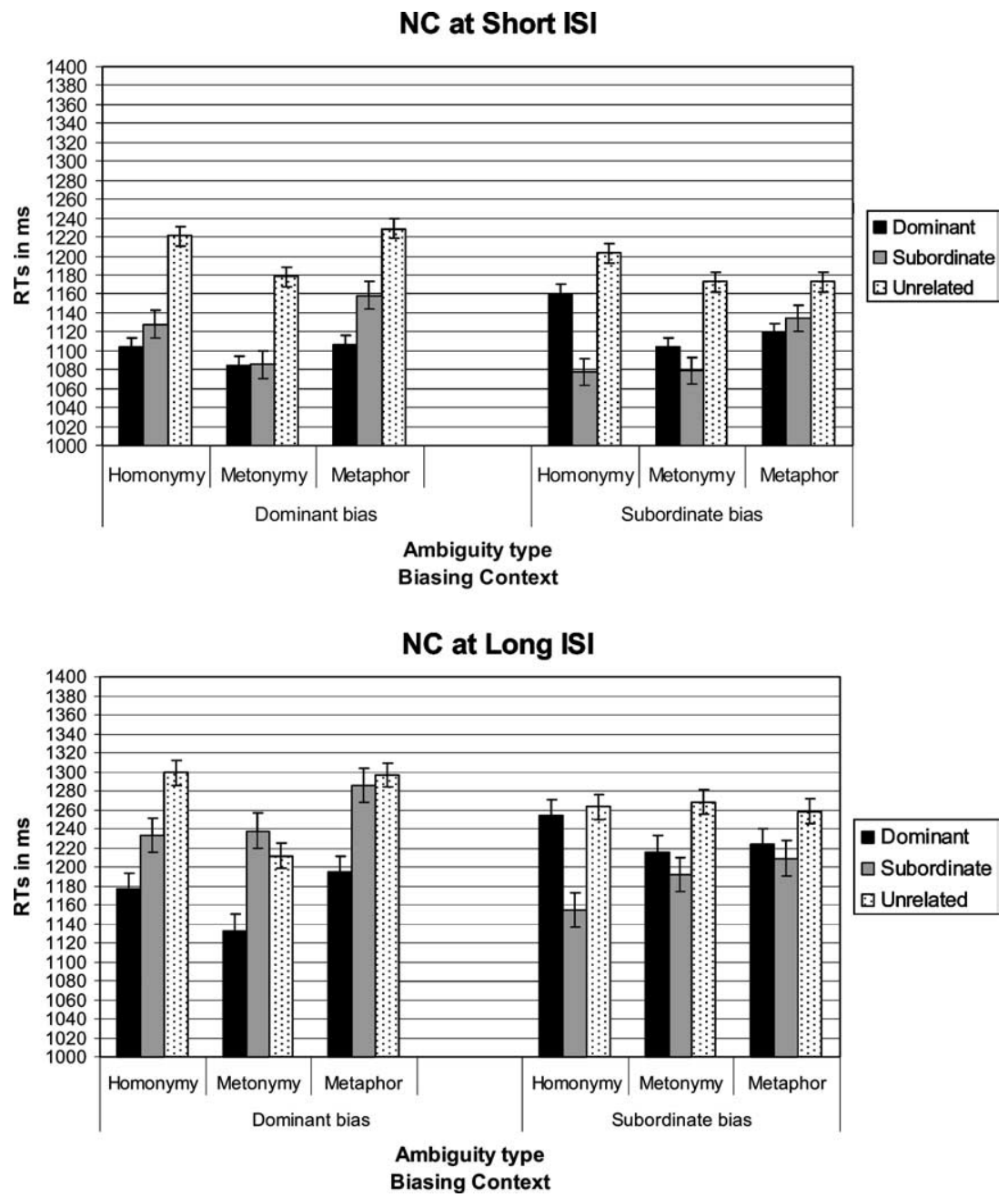

Fig. 1. Mean reaction times (and standard error) for normal control subjects (NC) at both ISIs (100 ms and 1000 ms) for control unrelated word targets (Unrelated), word targets related to the dominant meaning (Dominant), and word targets related to the subordinate meaning (Subordinate) following dominant (Dominant bias), and subordinate (Subordinate bias) biasing sentences for each ambiguity type (Homonymy, Metonymy, and Metaphor).

not reveal any differences of interest. However, post hoc analysis of the Meaning bias $\times$ Target type interaction revealed that after dominant-meaning biasing sentences, only RTs to dominant-related targets were significantly faster than to unrelated targets. Inspection of the individual data revealed that this pattern of performance was evidenced by $100 \%$ of LHD individuals. On the other hand, after subordinate-meaning biasing sentences, RTs to both dominant- and subordinate-related targets were significantly faster than to unrelated targets (shown by $100 \%$ of LHD patients) (see Fig. 2).

Although the ISI $\times$ Meaning $\times$ Target interaction did not reach statistical significance (and only showed a trend), it is interesting to note that at the short ISI, both contextually appropriate and inappropriate targets were responded to faster than unrelated targets for both dominant-meaning and subordinate-meaning biasing sentences (as evidenced by 100\% of LHD subjects for contextually appropriate targets and $77.7 \%$ of LHD sub- jects for contextually inappropriate targets) (see Fig. 2). On the other hand, looking at the long ISI, after dominant-meaning biasing sentences, $77.7 \%$ of LHD subjects exhibited faster RTs only to dominant-related targets than to unrelated targets, while after subordinate-meaning biasing sentences, RTs to both dominant- and subordinate-related targets were faster than to unrelated targets (shown by $100 \%$ of LHD subjects) (see Fig. 2).

\section{3. $R H D$ subjects}

For the RHD subjects, errors and outliers $( \pm 2 S D)$ comprised $11.88 \%$ of the data for the short ISI $(100 \mathrm{~ms})$ and $10.99 \%$ for the long $(1000 \mathrm{~ms})$ ISI.

The ISI (short, long) $\times$ Meaning bias (dominant, subordinate) $\times$ Ambiguity type (homonymy, metonymy, metaphor) $\times$ Target type (dominant-related, subordinate-related, unrelated) ANOVA revealed significant main effects of Ambiguity type $[F 1(2,14)=4.73, p<.05$; 

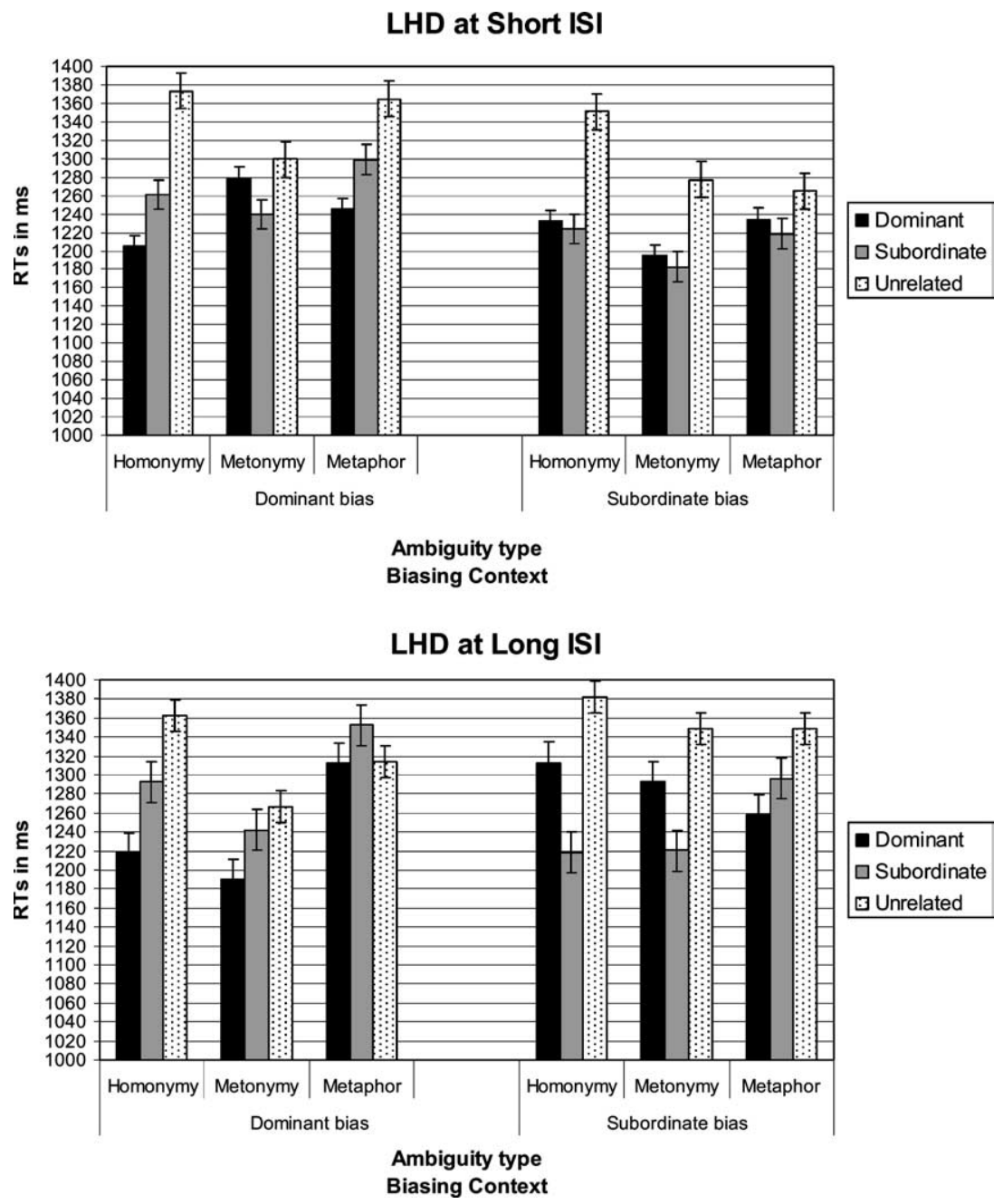

Fig. 2. Mean reaction times (and standard error) for left-hemisphere damaged non-fluent aphasic subjects (LHD) at both ISIs (100 ms and $1000 \mathrm{~ms}$ ) for control unrelated word targets (Unrelated), word targets related to the dominant meaning (Dominant), and word targets related to the subordinate meaning (Subordinate) following dominant (Dominant bias), and subordinate (Subordinate bias) biasing sentences for each ambiguity type (Homonymy, Metonymy, and Metaphor).

$F(2,612)=5.28, p<.01]$, and Target type $[F 1(2,14)=$ $18.42, p<.001 ; F 2(2,612)=29.91, p<.0001]$.

There were also significant two-way interaction effects of ISI $\times$ Meaning bias (for subjects) $[F 1(1,7)=5.74$, $p<.05 ; F 2(1,612)=3.24, p<.07]$, Meaning bias $\times$ Target type $[F 1(2,14)=11.17, p<.01 ; F 2(2,612)=5.62, p<.01]$, and Ambiguity type $\times$ Target type $[F 1(4,28)=5.12$, $p<.01 ; F 2(4,612)=3.36, p<.01]$.

Post hoc comparisons using the Duncan test $(p<.05)$ to further explore the ISI $\times$ Meaning bias interaction did not reveal any differences of interest. In contrast, post hoc comparisons of the Meaning bias $\times$ Target type interaction revealed that after dominant-meaning biasing sentences, RTs to both dominant- and subordinaterelated targets were significantly faster than to unrelated targets (pattern of facilitation shown by 100 and $75 \%$ of RHD patients, respectively). Similarly, after subordinate-meaning biasing sentences, RTs to both dominantand subordinate-related targets were significantly faster than to unrelated targets (see Fig. 3). This pattern of facilitation was shown by $87.5 \%$ of RHD individuals.

Furthermore, post hoc comparisons exploring the Ambiguity type $\times$ Target type interaction revealed that for homonymy and metonymy, RTs to both dominantand subordinate-related targets (which did not differ from each other) were significantly faster than to unrelated control targets (see Fig. 3). Inspection of the individual data revealed that this pattern of performance was evidenced by $100 \%$ of RHD individuals for homonymy, and by $75 \%$ of RHD patients for metonymy. For metaphor, on the other hand, RTs to dominant-related targets were significantly faster than to both subordinate-related targets (as evidenced by $75 \%$ of RHD individuals) and unrelated targets (shown by $100 \%$ of RHD individuals) (see Fig. 3). Subordinate-related targets did not show any facilitation relative to unrelated targets (as evidenced by $62.5 \%$ of RHD patients). There were no obvious characteristics (either in terms of age or in terms 

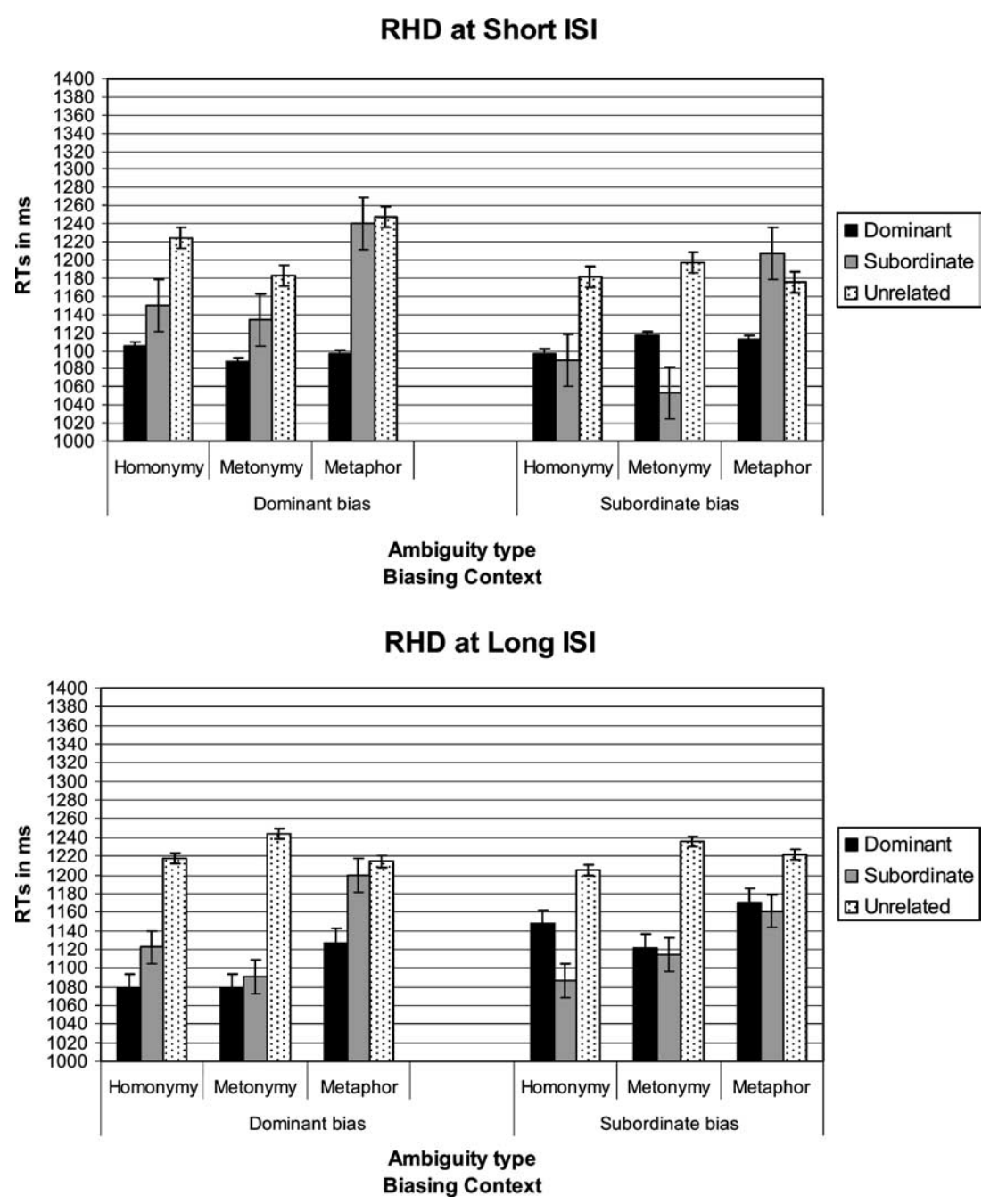

Fig. 3. Mean reaction times (and standard error) for right-hemisphere damaged subjects (RHD) at both ISIs (100 ms and $1000 \mathrm{~ms}$ ) for control unrelated word targets (Unrelated), word targets related to the dominant meaning (Dominant), and word targets related to the subordinate meaning (Subordinate) following dominant (Dominant bias), and subordinate (Subordinate bias) biasing sentences for each ambiguity type (Homonymy, Metonymy, and Metaphor).

of lesion site) that differentiated those individuals who conformed to the group pattern from those who did not. Thus, in the present study, the performance of the 3 RHD participants with predominantly subcortical lesions did not differ from the performance of the other 5 RHD participants with cortical lesions (but cf. Copland, Chenery, \& Murdoch, 2000; Copland, Chenery, \& Murdoch, 2001 for results on lexical ambiguity processing following LH subcortical lesions).

\section{Discussion}

The present study aimed to investigate the timecourse of meaning activation and the effects of sentential context on the processing of ambiguous words. Importantly, by exploiting the distinctions among different types of ambiguous words (i.e., homonyms, metonymies, and metaphors), the study also explored the effects of the strength of the semantic relations that hold between their meanings (or senses) in an attempt to test the "suppression deficit" (Tompkins \& Lehman, 1998) and the "coarse semantic coding" (Beeman, 1993) hypotheses of $\mathrm{RH}$ language function and dysfunction. Although the results failed to support the strongest versions of either the "suppression deficit" or the "coarse semantic coding" hypothesis, they seem to indicate that RH damage leads to impairments in the effective use of sentential context and to changes in the normal patterns of the time-course of activation. As a result, RHD patients seem to have difficulties selectively activating the appropriate meaning of ambiguous words, and ultimately, inhibiting inappropriate meanings.

With respect to normal control subjects, the present findings are consistent with the existing psycholinguistic literature that shows that both context and interstimulus interval affect the meaning activation process. More specifically, previous studies with young healthy adults have 
shown that at a short ISI (less than $200 \mathrm{~ms}$ ), all meanings of ambiguous words are activated even in the presence of a biasing context (e.g., Seidenberg et al., 1982; Swaab et al., 2003; Swinney, 1979). However, at a longer ISI (more than $500 \mathrm{~ms}$ ), there is evidence that only the contextually appropriate meaning of ambiguous words remains activated (e.g., Swinney, 1979). The present study replicated these findings with older non-braindamaged participants. In particular, it was found that at the short delay $(100 \mathrm{~ms})$, targets related to both the dominant and subordinate meanings of ambiguous words showed facilitation relative to unrelated control targets, irrespective of the biasing context (whether context biased the dominant or the subordinate meaning). However, at the longer delay $(1000 \mathrm{~ms})$, the normal control subject group showed effects of context, as only the contextually appropriate targets (either dominant or subordinate) were facilitated relative to unrelated control targets. Furthermore, these findings held for all three types of ambiguous words (i.e., homonymy, metonymy, and metaphor), indicating that in the presence of biasing context, the strength of the semantic relation between the meanings (or senses) of ambiguous words does not critically influence activation patterns. In other words, the presence of context can facilitate access even to meanings that may not be typically available in isolation (e.g., the subordinate meanings of metaphors; see Klepousniotou \& Baum, 2005).

Thus, the findings for the normal control subjects contribute to our understanding of the importance of the semantic relations between the multiple meanings/ senses of ambiguous words. The present findings indicate that the strength of the semantic relation among the multiple meanings of homonymous (no relation) and metonymous (close relation) words does not seem to play a role in the activation process when the ambiguous words serve as primes. These findings, thus, do not make a distinction in the processing of words with multiple unrelated meanings (i.e., homonymy) and words with multiple related senses (i.e., metonymy). Nevertheless, according to theoretical and computational linguists (e.g., Cruse, 1986; Lyons, 1977; Pustejovsky, 1995), homonymous and metonymous words are assumed to represent two end-points on the continuum from multiple unrelated meanings (in the case of homonymy) to multiple related senses (in the case of metonymy). Previous psycholinguistic studies have also provided evidence that homonymous and polysemous words are processed differentially and, thus, may be stored differently in the mental lexicon (e.g., Azuma \& Van Orden, 1997; Frazier \& Rayner, 1990; Klepousniotou, 2002; Rodd et al., 2002; Rubenstein et al., 1971; but cf. Klein \& Murphy, 2001, 2002). One possible account of the disparate findings relates to crucial differences in the methodology of the present experiments as compared to previous studies. In particular, previous studies that have shown differential processing for homonymous and metonymous words have used the ambiguous lexical items as targets, thus measuring the effect (or cost) of having multiple meanings, as opposed to multiple senses, on the activation process. The present study used the ambiguous lexical items as primes, measuring whether and how they can facilitate access to word associates that are related to their dominant or subordinate meanings/senses. Therefore, the present study was not specifically designed to assess the cost of having multiple meanings or senses, but rather whether participants can access the multiple meanings/senses of ambiguous words when they appear in sentential context. The findings of the present study suggest that when the ambiguous words serve as primes, there are no differences in the activation patterns for their multiple meanings/senses.

Turning to the brain-damaged groups, previous studies (e.g., Grindrod \& Baum, 2003; Hagoort, 1993; Swaab et al., 1998; Tompkins et al., 1997; Tompkins et al., 2000) have demonstrated differential effects of $\mathrm{LH}$ and $\mathrm{RH}$ lesions on the processing of ambiguous words. With respect to LHD non-fluent aphasic patients, who in the present study showed performance largely parallel to that of the normal control subjects, both context and interstimulus interval seem to have influenced the processing of ambiguous words. Importantly, the LHD non-fluent aphasic patients were, as expected, able to understand the short, canonical, active voice sentences used in the present study (see also Caramazza \& Zurif, 1976; Berndt, Mitchum, \& Wayland, 1997), indicating that the presence of some types of context (such as the ones used here) may assist linguistic processing in these patients. Nevertheless, the data for the LHD non-fluent aphasic patients should be interpreted with caution, given that the results did not always reach statistical significance. In the present study, differences in activation were observed between the shorter and longer delays. In particular, at the short $(100 \mathrm{~ms})$ delay, both contextually appropriate and inappropriate targets were facilitated relative to unrelated targets. On the other hand, at the long $(1000 \mathrm{~ms})$ ISI, after dominant-biasing sentences, only dominant-related targets were facilitated, while after subordinate-biasing sentences, facilitation effects were still observed for both dominant- and subordinaterelated targets, indicating that the LHD non-fluent aphasic patients were influenced by both context and meaning frequency. Most importantly, however, the LHD non-fluent aphasic patients showed similar performance for all three types of ambiguous words (i.e., homonymy, metonymy, and metaphor), as did the normal control subjects, indicating that they can also activate meanings that may not be typically available in isolation (e.g., subordinate meanings of metaphors). The present results are consistent with the findings of some previous studies that have shown that LHD non-fluent aphasic patients demonstrate relatively intact processing of 
ambiguous words in that they can access alternate meanings (e.g., Grindrod \& Baum, 2003; Hagoort, 1993; Milberg \& Blumstein, 1981; Swaab et al., 1998; but cf. Prather, Zurif, Love, \& Brownell, 1997; Swinney, Zurif, $\&$ Nicol, 1989 for evidence that Broca's aphasic patients exhibit slower than normal activation patterns and facilitation effects only for dominant meanings of homonymous words).

Turning to RHD patients, recall that exploiting the particularities of the three types of lexical ambiguity (i.e., homonymy, metonymy, and metaphor), the present study set out to test the predictions of the "suppression deficit" (Tompkins \& Lehman, 1998) and the "coarse semantic coding" (Beeman, 1993) hypotheses that have been proposed to account for the deficits observed after RH damage. The two hypotheses make different predictions about the performance of individuals with RHD, if the linguistic distinctions of lexical ambiguity are taken into consideration. In particular, as described earlier, the strongest form of the "coarse semantic coding" hypothesis (Beeman, 1993) would predict that RHD patients should be differentially impaired at accessing alternative meanings of homonymous but not metonymous words. Alternatively, the strongest form of the "suppression deficit" hypothesis (Tompkins \& Lehman, 1998) would predict that RHD patients should be able to initially activate all meanings, but eventually (at the longer ISI) they should be equally impaired at suppressing the alternative meanings/senses of all types of lexical ambiguity. However, the present findings did not reveal exactly such patterns of lexical ambiguity processing. Previous priming studies with RHD patients have shown that they experience problems inhibiting the contextually inappropriate meanings of homonymous words (Tompkins et al., 1997, 2000), and that access to context is disrupted (Grindrod \& Baum, 2003). The findings of the present study are consistent with such previous studies, in that the performance of RHD patients did not differ over the time-course of processing. For both ISIs, facilitation effects were observed for both dominant- and subordinate-related targets compared to unrelated control targets, largely irrespective of contextual bias (i.e., whether targets were presented after dominant-meaning or subordinate-meaning biasing sentences). Thus, these findings are consistent with previous research that has shown that RHD patients are impaired in their ability to effectively use context (e.g., Beeman, 1993; Grindrod \& Baum, 2003; Schmitzer et al., 1997; Tompkins et al., 2000; but cf. Leonard \& Baum, 1998; Leonard, Baum, \& Pell, 2001; Leonard, Waters, \& Caplan, 1997). Consistent with previous findings (e.g., Tompkins et al., 1997; Tompkins et al., 2000), the present results seem to point toward a lack of time-course effects, leading to an inability of RHD patients to effectively select only the contextually appropriate meaning and eventually suppress inappropriate ones.
Importantly, the findings reported above were observed for both homonymous and metonymous ambiguous words. Thus, the present study suggests that despite differences in the word types, in the presence of biasing context, the strength of the semantic relation among the meanings (or senses) of ambiguous words (more specifically homonymous and metonymous words) does not seem to significantly affect processing patterns in RHD patients. However, in contrast to the normal control subjects and the LHD non-fluent aphasic patients, RHD patients did show differential effects for metaphorically ambiguous words, for which only the dominant meaning was facilitated, regardless of biasing context and interstimulus interval. This finding, which is consistent with earlier off-line studies by Brownell et al. $(1984,1990)$ that also showed impairments in the appreciation of metaphorical meanings, suggests that RHD patients may have a particular problem activating the subordinate, figurative meaning of metaphors (in addition to their difficulties appreciating context and eventually suppressing inappropriate meanings). This finding is also consistent with the theoretical linguistics literature that holds that metaphorical senses tend to be inconsistent and unsystematic (Apresjan, 1974) and therefore more loosely related than the systematic and predictable metonymic senses. Metaphors are thought to have more distantly related semantic features that probably need a highly specific context situation to be triggered (or even be computed on demand), and even in the presence of an appropriate context situation, access to the secondary, metaphorical senses of these words seems to be difficult for RHD patients. In fact, previous studies (e.g., Beeman, 1993; Grindrod \& Baum, 2003; Schmitzer et al., 1997; Tompkins et al., 2000; but cf. Leonard \& Baum, 1998; Leonard et al., 2001; Leonard et al., 1997), as well as the present results, indicate that RHD patients have difficulties with the appreciation of context. Given the inability of RHD patients to effectively use context, it is conceivable that when the activation of the subordinate meaning heavily relies on contextual cues (as in the case of metaphorical polysemy), the processing abilities of RHD individuals are severely compromised. As a result, although the biasing context assisted the activation of the secondary meanings of metaphors in the normal control subject population, as well as in the LHD nonfluent aphasic population, no such effects were observed for the RHD individuals.

The results of the present study are contrary to the strongest expectations of both the "coarse semantic coding" and the "suppression deficit" hypotheses of RH language abilities. In particular, there were no processing differences in the RHD patients between homonymous and metonymous words that would provide support to the predictions of the strongest form of the "coarse semantic coding" hypothesis. Similarly, RHD patients did not exhibit deficits in the suppression of 
contextually inappropriate meanings across all types of lexical ambiguity (i.e., homonymy, metonymy, and metaphor) which would provide support to the predictions of the strongest form of the "suppression deficit" hypothesis. Nevertheless, RHD patients did show impairments in the time-course of processing and an inability to fully appreciate context. Thus, the present findings could be interpreted as supporting a softer version of the "suppression deficit" hypothesis. In particular, RHD patients showed facilitation for both dominant and subordinate meanings (at least for homonymous and metonymous words) largely irrespective of contextual bias and interstimulus interval. Therefore, even the presence of biasing context did not influence activation patterns by limiting activation (at least at the longer delay) to the contextually appropriate meaning alone. In addition, RHD patients showed a selective impairment in the appreciation of secondary/ figurative meanings of metaphorical polysemy. Thus, the present findings seem to indicate that individuals with RHD may, indeed, have a deficit suppressing alternative, contextually inappropriate meanings of ambiguous words (confined to homonymy and metonymy) as well as a particular impairment in the appreciation of figurative meanings.

\section{Acknowledgments}

The research reported here is part of the doctoral dissertation of the first author. This research was supported by a McGill Majors Fellowship and a Studentship from the Faculty of Medicine, McGill University to the first author and by a grant from the Fonds pour la Formation de Chercheurs et l'Aide à la Recherche (FCAR, now FRNTQ) to the second author. We thank the patients and the normal control subjects who participated in the study. We also thank Phaedra Royle for recording the stimuli. Finally, we thank the editor and the reviewers for their useful comments and suggestions.

\section{Appendix A}

Experimental word stimuli for the sentence priming study

\begin{tabular}{llll}
\hline $\begin{array}{l}\text { Ambiguous word prime } \\
\text { (in sentence-final position) }\end{array}$ & Target & \\
\cline { 2 - 4 } & Dominant & Subordinate & $\begin{array}{l}\text { Unrelated } \\
\text { control }\end{array}$ \\
\hline Homonymy & & & \\
ball & round & dance & battle \\
count & eighty & duke & rake \\
file & drawer & carpenter & trumpet \\
march & april & soldiers & portion \\
park & bench & vehicle & context \\
yard & grass & mile & sin \\
drill & machine & practice & marriage \\
fan & breeze & sport & tile
\end{tabular}

Appendix A. (continued)

\begin{tabular}{|c|c|c|c|}
\hline \multirow{2}{*}{$\begin{array}{l}\text { Ambiguous word prime } \\
\text { (in sentence-final position) }\end{array}$} & \multicolumn{3}{|l|}{ Target } \\
\hline & Dominant & Subordinate & $\begin{array}{l}\text { Unrelated } \\
\text { control }\end{array}$ \\
\hline$\overline{\operatorname{mint}}$ & candy & coin & ruin \\
\hline pen & ink & crib & ramp \\
\hline port & dock & brandy & lotion \\
\hline toll & fee & bell & flame \\
\hline bluff & fake & cliff & button \\
\hline bolt & screw & jump & joke \\
\hline foil & tin & sword & pearl \\
\hline mole & dig & wart & tide \\
\hline perch & branch & fish & crime \\
\hline punch & fist & fruit & cloud \\
\hline \multicolumn{4}{|l|}{ Metaphor } \\
\hline arm & wrist & couch & reef \\
\hline lip & chap & rim & swamp \\
\hline mouth & eat & flow & rifle \\
\hline neck & throat & narrow & motor \\
\hline shoulder & blade & sleeve & ballot \\
\hline tongue & lick & laces & broom \\
\hline chicken & hen & scared & soap \\
\hline cow & milk & fat & lake \\
\hline fox & hound & sly & spoon \\
\hline parrot & pirate & mimic & comet \\
\hline pig & mud & dirty & clerk \\
\hline worm & snail & slimy & coupon \\
\hline doll & toy & cute & hook \\
\hline gem & stone & unique & smile \\
\hline nucleus & electron & boss & motel \\
\hline pillar & column & model & chapter \\
\hline spice & herb & thrill & comb \\
\hline star & universe & famous & coffee \\
\hline \multicolumn{4}{|l|}{ Metonymy } \\
\hline bag & luggage & garbage & terrain \\
\hline barrel & keg & pickles & gust \\
\hline bottle & cork & alcohol & ghost \\
\hline basket & weave & laundry & dove \\
\hline cup & bowl & tea & fog \\
\hline glass & crystal & juice & thread \\
\hline lemon & lime & squeeze & silk \\
\hline maple & leaf & syrup & choir \\
\hline onion & garlic & salad & cement \\
\hline pine & tree & smell & trend \\
\hline potato & spud & mash & claw \\
\hline rabbit & hop & stew & chalk \\
\hline alley & lane & cat & shirt \\
\hline arena & stadium & concert & carbon \\
\hline cage & metal & animal & credit \\
\hline chimney & brick & sweep & nurse \\
\hline pipe & tube & smoke & tape \\
\hline theater & screen & drama & pilot \\
\hline
\end{tabular}

\section{References}

Anaki, D., Faust, M., \& Kravetz, S. (1998). Cerebral hemispheric asymmetries in processing lexical metaphors. Neuropsychologia, $36,691-700$.

Apresjan, J. (1974). Regular polysemy. Linguistics, 142, 5-32.

Azuma, T., \& Van Orden, G. C. (1997). Why SAFE is better than FAST: The relatedness of a word's meanings affects lexical decision times. Journal of Memory and Language, 36, 484504. 
Beeman, M. (1993). Semantic processing in the right hemisphere may contribute to drawing inferences from discourse. Brain and Language, 44, 80-120.

Beeman, M. (1998). Coarse semantic coding and discourse comprehension. In M. Beeman \& C. Chiarello (Eds.), Right hemisphere language comprehension (pp. 255-284). Mahwah, NJ: Lawrence Erlbaum Associates.

Berndt, R. S., Mitchum, C. C., \& Wayland, S. (1997). Patterns of sentence comprehension in aphasia: A consideration of three hypotheses. Brain and Language, 60, 197-221.

Brownell, H. H. (1998). Appreciation of metaphoric and connotative word meaning by brain-damaged patients. In C. Chiarello (Ed.), Right hemisphere contributions to lexical semantics (pp. 19-31). Berlin: Springer-Verlag.

Brownell, H. H., Potter, H. H., Michelow, D., \& Gardner, H. (1984). Sensitivity to lexical denotation and connotation in brain-damaged patients: A double dissociation?. Brain and Language, 22, 253-265.

Brownell, H. H., Simpson, T. L., Bihrle, A. M., Potter, H. H., \& Gardner, H. (1990). Appreciation of metaphoric alternative word meanings by left and right brain-damaged patients. Neuropsychologia, $28,375-383$.

Burgess, C., \& Simpson, G. B. (1988). Cerebral hemispheric mechanisms in the retrieval of ambiguous word meanings. Brain and Language, 33, 86-103.

Caplan, D. (1992). Language: structure, process, and disorders. Cambridge, MA: MIT Press.

Caramazza, A., \& Zurif, E. (1976). Dissociation of algorithmic and heuristic processes in language comprehension: Evidence from aphasia. Brain and Language, 3, 572-582.

Coney, J., \& Evans, K. D. (2000). Hemispheric asymmetries in the resolution of lexical ambiguity. Neuropsychologia, 38, 272-282.

Copland, D. A., Chenery, H. J., \& Murdoch, B. E. (2000). Understanding ambiguous words in biased sentences: Evidence of transient contextual effects in individuals with nonthalamic subcortical lesions and Parkinson's disease. Cortex, 36, 601-622.

Copland, D. A., Chenery, H. J., \& Murdoch, B. E. (2001). Discourse priming of homophones in individuals with dominant nonthalamic subcortical lesions, cortical lesions and Parkinson's disease. Journal of Clinical and Experimental Neuropsychology, 23, 538-556.

Cruse, D. A. (1986). Lexical Semantics. CUP.

Duffy, S. A., Morris, R. K., \& Rayner, K. (1988). Lexical ambiguity and fixation times in reading. Journal of Memory and Language, 27, 429-446.

Faust, M. E., \& Gernsbacher, M. A. (1996). Cerebral mechanisms for suppression of inappropriate information during sentence comprehension. Brain and Language, 53, 234-259.

Faust, M., Kravetz, S., \& Netzer, E. (2002). Effects of sentential context on the processing of unambiguous words by the two cerebral hemispheres. Brain and Language, 80, 438-448.

Folstein, M. F., Folstein, S. E., \& McHugh, P. R. (1975). "Mini-mental state": A practical method for grading the cognitive state of patients for the clinician. Journal of Psychiatric Research, 12, 189-198.

Francis, W. N., \& Kucera, H. (1982). Frequency analysis of english usage: Lexicon and grammar. Boston: Houghton Mifflin.

Frazier, L., \& Rayner, K. (1990). Taking on semantic commitments: Processing multiple meanings vs. multiple senses. Journal of Memory and Language, 29, 181-200.

Goodglass, H., Kaplan, E., \& Barresi, B. (2001). The assessment of aphasia and related disorders. Philadelphia/Baltimore: Lippincott/ Williams and Wilkins.

Grindrod, C. M., \& Baum, S. R. (2003). Sensitivity to local sentence context information in lexical ambiguity resolution: Evidence from left- and right-hemisphere-damaged individuals. Brain and Language, $85,503-523$.

Hagoort, P. (1993). Impairments of lexical-semantic processing in aphasia: Evidence from the processing of lexical ambiguities. Brain and Language, 45, 189-232.
Hagoort, P., Brown, C. M., \& Swaab, T. Y. (1996). Lexical-semantic event-related potential effects in patients with left hemisphere lesions and aphasia, and patients with right hemisphere lesions without aphasia. Brain, 119, 627-649.

Kaplan, E., Goodglass, H., \& Weintraub, S. (1983). Boston naming test. Philadelphia, PA: Lea and Febiger.

Klein, D. E., \& Murphy, G. L. (2001). The representation of polysemous words. Journal of Memory and Language, 45, 259-282.

Klein, D. E., \& Murphy, G. L. (2002). Paper has been my ruin: conceptual relations of polysemous senses. Journal of Memory and Language, 47, 548-570.

Klepousniotou, E. (2002). The processing of lexical ambiguity: Homonymy and polysemy in the mental lexicon. Brain and Language, $81,205-223$.

Klepousniotou, E., \& Baum, S. R. (2005). Unilateral brain damage effects on processing homonymous and polysemous words. Brain and Language, doi:10.1016/j.band1.2004.10.011.

Leonard, C. L., \& Baum, S. R. (1998). On-line evidence for context use by right-brain-damaged patients. Journal of Cognitive Neuroscience, 10, 499-508.

Leonard, C. L., Baum, S. R., \& Pell, M. D. (2001). The effect of compressed speech on the ability of right-hemisphere-damaged patients to use context. Cortex, 37, 327-344.

Leonard, C. L., Waters, G. S., \& Caplan, D. (1997). The use of contextual information by right-brain-damaged individuals in the resolution of ambiguous pronouns. Brain and Language, 57, 309-342.

Lyons, J. (1977). Semantics. Vol. 1-2. CUP.

Mertus, J. (2000). Brown lab interactive speech system [Computer software ]. Providence, RI: Brown University.

Milberg, W., \& Blumstein, S. E. (1981). Lexical decision and aphasia: Evidence for semantic processing. Brain and Language, 14, 371385.

Milberg, W., Blumstein, S. E., \& Dworetzky, B. (1987). Processing of lexical ambiguities in aphasia. Brain and Language, 31, 138-150.

Neill, W. T., Hilliard, D. V., \& Cooper, E. (1988). The detection of lexical ambiguity: Evidence for context-sensitive parallel access. Journal of Memory and Language, 27, 279-287.

Nelson, D. L., McEvoy, C. L., \& Schreiber, T. A. (1998). The University of Florida word association, rhyme and word fragment norms. Available from: http://www.usf.edu/FreeAssociation/.

Nelson, D. L., McEvoy, C. L., Walling, J. R., \& Wheeler, J. W., Jr. (1980). The University of South Florida homograph norms. Behavior Research Methods and Instrumentation, 12, 16-37.

Nunberg, G. (1979). The non-uniqueness of semantic solutions: polysemy. Linguistics and Philosophy, 3, 143-184.

Prather, P. A., Zurif, E., Love, T., \& Brownell, H. (1997). Speed of lexical activation in nonfluent Broca's aphasia and fluent Wernicke's aphasia. Brain and Language, 59, 391-411.

Pustejovsky, J. (1995). The generative lexicon. Cambridge, MA: MIT Press.

Rodd, J., Gaskell, G., \& Marslen-Wilson, W. (2002). Making sense of semantic ambiguity: Semantic competition in lexical access. Journal of Memory and Language, 46, 245-266.

Rubenstein, H., Lewis, S. S., \& Rubenstein, M. A. (1971). Homographic entries in the internal lexicon: Effects of systematicity and relative frequency of meanings. Journal of Verbal Learning and Verbal Behavior, 10, 57-62.

Schmitzer, A. B., Strauss, M., \& DeMarco, S. (1997). Contextual influences on comprehension of multiple-meaning words by right hemisphere brain-damaged and non-brain-damaged adults. Aphasiology, 11, 447-459.

Schreuder, R., \& Flores d' Arcais, G. B. (1989). Psycholinguistic issues in the lexical representation of meaning. In W. Marslen-Wilson (Ed.), Lexical Representation and Process (pp. 409-436). Cambridge, MA: MIT Press.

Seidenberg, M. S., Tanenhaus, M. K., Leiman, J. M., \& Bienkowski, M. (1982). Automatic access of the meanings of ambiguous words in 
context: Some limitations of knowledge-based processing. Cognitive Psychology, 14, 489-537.

Simpson, G. B. (1984). Lexical ambiguity and its role in models of word recognition. Psychological Bulletin, 96, 316-340.

Simpson, G. B. (1994). Context and the processing of ambiguous words. In M. A. Gernsbacher (Ed.), Handbook of Psycholinguistics. San Diego: Academic Press.

Simpson, G. B., \& Krueger, M. A. (1991). Selective access of homograph meanings in sentence context. Journal of Memory and Language, 30, 627-643.

Stevens, J. (1996). Applied multivariate statistics for the social sciences (3rd ed.). Mahwah, NJ: Lawrence Erlbaum Associates.

Swaab, T. Y., Brown, C., \& Hagoort, P. (1998). Understanding ambiguous words in sentence contexts: Electrophysiological evidence for delayed contextual selection in Broca's aphasia. Neuropsychologia, $36,737-761$.

Swaab, T. Y., Brown, C., \& Hagoort, P. (2003). Understanding words in sentence contexts: The time course of ambiguity resolution. Brain and Language, 86, 326-343.

Swinney, D. A. (1979). Lexical access during sentence comprehension: (Re)consideration of context effects. Journal of Verbal Learning and Verbal Behavior, 18, 645-659.

Swinney, D., Zurif, E., \& Nicol, J. (1989). The effects of focal brain damage on sentence processing: An examination of the neurological organization of a mental module. Journal of Cognitive Neuroscience, 1, 25-37.

Tanenhaus, M. K., Leiman, J. M., \& Seidenberg, M. S. (1979). Evidence for multiple stages in the processing of ambiguous words in syntactic contexts. Journal of Verbal Learning and Verbal Behavior, 18, 427-440.
Titone, D. (1998). Hemispheric differences in context sensitivity during lexical ambiguity resolution. Brain and Language, 65, 361-394.

Tompkins, C. A., Baumgaertner, A., Lehman, M. T., \& Fassbinder, W. (2000). Mechanisms of discourse comprehension impairment after right hemisphere brain damage: Suppression in lexical ambiguity resolution. Journal of Speech, Language, and Hearing Research, 43, 62-78.

Tompkins, C. A., Baumgaertner, A., Lehman, M. T., \& Fossett, T. R. D. (1997). Suppression and discourse comprehension in right braindamaged adults: A preliminary report. Aphasiology, 11, 505-519.

Tompkins, C. A., \& Lehman, M. T. (1998). Interpreting intended meanings after right hemisphere brain damage: An analysis of evidence, potential accounts, and clinical implications. Topics in Stroke Rehabilitation, 5, 29-47.

Twilley, L. C., Dixon, P., Taylor, D., \& Clark, K. (1994). University of Alberta norms of relative meaning frequency for 566 homographs. Memory and Cognition, 22, 111-126.

Wechsler, D. W. (1987). Wechsler memory scale revised. San Antonio: Harcourt, Brace and Jovanovich.

Wiig, E. H., \& Secord, W. (1987). Test of language competenceexpanded edition. San Antonio, TX: Harcourt, Brace and Jovanovich.

Williams, J. N. (1992). Processing polysemous words in context: Evidence for interrelated meanings. Journal of Psycholinguistic Research, 21, 193-218.

Wilson, B., Cockburn, J., \& Halligan, P. (1987). Behavioural inattention test. Titchfield, UK: Thames Valley Test Company.

Winner, E., \& Gardner, H. (1977). The comprehension of metaphor in brain-damaged patients. Brain, 100, 719-727. 